\title{
El uso del espacio verde urbano: entre lo privado y lo público, estética y rendimiento económico. La Casa de Campo, parque de Madrid
}

\author{
WALTRAUD MÜLLAUER-SEICHTER \\ Departamento de Antropología de España y América \\ CSIC. Madrid
}

En Madrid tiene el Rey una recreación a la parte del rio Manzanares, que se llama la Casa de Campo, en que tiene una pequeña aposenta de oficinas, jardines, buertas, fuentes, estanques y sitio, en que se cazan conejos, que se ve desde el Alcázar, cerca a la parte del Occidente, con Alcayde el Duque de Lerma, tiene su teniente, capitán, jardineros, arbolistas y cuerdas, que tienen cuenta con el límite $y$ contorno de su distrito. (Busto y de Jado Cajigal 1876: 2) ${ }^{1}$

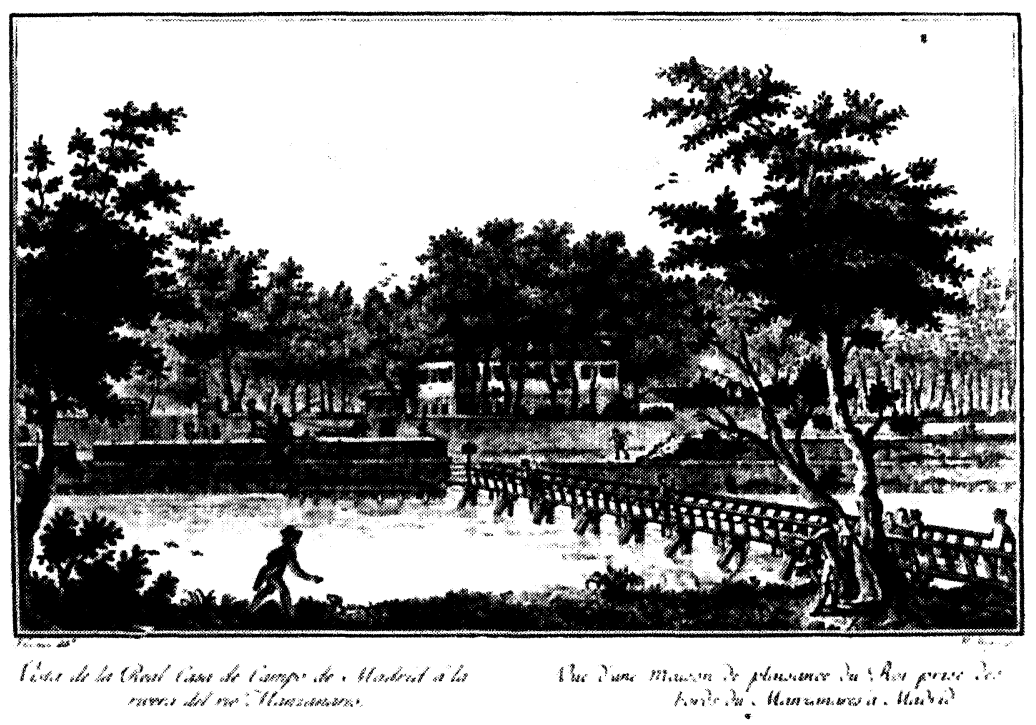

Figura 1.-José Gómez de Navia: Vista de la Real Casa de Campo de Madrid desde la ribera del río Manzanares. Museo Municipal de Madrid.

* El presente artículo ha sido elaborado dentro del proyecto de investigación PB 1182 Análisis antropológico de las manifestaciones de culto a santos y vírgenes en Madrid.

${ }^{1}$ Por indicación de la editora, Matilde Fernández Montes, hemos modernizado todo el sistema de puntuación en las citas. 


\section{"NATURALEZA URBANIZADA"}

"En un plano del puro pensamiento los conceptos de ciudad y naturaleza responden a ideales, es decir, ambos son conceptos imaginarios que designan realidades inexistentes" (Rubio Díaz 1993: 36). Siguiendo este enfoque teórico, tanto el territorio, lo que llamamos naturaleza, como la ciudad son, cada vez más, representaciones idealizadas que se distinguen bastante de las idealizaciones que muestra el imaginario colectivo. Incluso, desde el punto de vista sociopolítico, el desarrollo de las zonas verdes en la urbe pone de manifiesto su relación con las estrategias del poder.

Los paisajes y los jardines representan no simplemente una parte del arte histórico-arquitectónico, sino que también expresan maneras de asociar ideas. Como muestra María Jesús Buxó en su estudio sobre jardines en Cataluña (Buxó i Rey 1999), estos espacios, transformados en lugares culturales, pueden proporcionarnos información sobre la construcción de representaciones históricas y políticas de la identidad étnica, social o genérica:

cabría destacar la comprensión del jardín y el patio como zona de libertad donde airear uno de los elementos constitutivos de la identidad étnica, la lengua catalana, cuando ésta encuentra sus cauces de expresión reprimidos en diferentes momentos de la historia. Así mientras en las escuelas se imparten las clases y se lee en castellano, en el jardín y en el patio se habla y se juega en catalán (Buxó i Rey 1999: 238).

La percepción de lo verde y, por lo tanto, su aprovechamiento individual más o menos excesivo interesa desde el punto de vista antropológico cuando se contempla en un contexto más amplio, es decir, cuando se compara la relación con los espacios verdes dentro de un eje espaciotemporal.

En su estudio sobre la clase media sueca del siglo pasado, Jonas Frykman y Orvar Löfgren (1987) aportan una visión del acercamiento de los suecos hacia la naturaleza del país nórdico que difiere bastante del uso y de la importancia que se daba en el ámbito español en esa misma época. Frykman y Löfgren explican la situación que se plantea a partir de la mitad del siglo XIX, hasta finales del mismo, cuando ya existía un movimiento naturalista, que tenía su expresión en instituciones como por ejemplo el Swedish Touring Club y superaba las fronteras de las clases sociales $^{2}$. Esta forma de ver el paisaje abarcaba no sólo su lado exótico,

\footnotetext{
${ }^{2}$ Frykman y Löfgren, 1987:59: [...] "Nature was animated into a symbol for Swedishness and a national fellowship above class bounderies. Now it was no longer
} 
sino sobre todo, la necesidad de individualismo y retiro en un ambiente natural ${ }^{3}$, lo que la gente buscaba y lo que deseaba encontrar, según éstos, era el silencio total y la contemplación. Frykman y Löfgren lo describen como un ritual hacia una vida pura con la que se pretende escapar de los quehaceres y ocupaciones estresantes de los centros urbanos. Por el contrario, según los autores que dan una visión de la vida cotidiana española, o más bien madrileña, los incentivos de los espacios verdes se centran en su aportación sociocultural. No eran precisamente el deseo de soledad y tranquilidad las razones de acudir a estos lugares. Lo que se buscaba en los paseos arbolados y en los parques era el encuentro, la relación social. Se iba para ver gente y para dejarse ver. Sobre las condiciones de los enclaves de tales encuentros escribió Fernández de los Ríos en su Guía de Madrid:

Desde la tala de sus bosques hasta fines del siglo pasado, la villa tenía dos únicos paseos el Prado de San Jerónimo y tal cual "pedazo de tierra con algunos árboles, ni muchos, ni galanes, ni grandes" caprichosamente arraigados a orillas del Manzanares, y distantes, en ruda pendiente, dos kilómetros de la población; pues aunque, además del pasajero Parque del Palacio ya existían los extensos de la Casa de Campo, Moncloa y Retiro, pertenecientes á los reyes, en algunos no tenía entrada el público, y donde se le permitía penetrar era con limitaciones tales, que equivalían á la clausura. (Fernández de los Ríos 1876: 325)

y más adelante sobre la necesidad de plazuelas arboladas en la capital:

En España, por desgracia, se practica este arte [jardinería] por una instintiva e imperfecta imitación; en ninguna cátedra ni escuela se explica ni se da á conocer por sus verdaderos principios. Así y todo, las plazuelas de la capital, desnudas y tristes hace pocos años, cuando tanta importancia adquirían los squares de Londres, París, Berlín y Viena y otras poblaciones de menor importancia, han llegado a estar bien cuidadas, demostrando gusto en el trazado de los pequeños jardines públicos y en la elección de los arbustos (Ibid.: 327).

\footnotetext{
the wild mountains or the stormy coast that were the favorite landscapes, but rather the nostalgic and melancholic settings: the whispering pine forest, the silent, starry winter night, the grove of young birch trees, the wood anemones in the forest clearing. The dramatic and exotic landscapes gaye way to the intimate and melancholy, but still it was the solitary landscape, uncontaminated by human precence, that was preferred".

${ }^{3}$ Frykman y Löfgren: (1987: 55): The new landscape aesthetics contained ideas about what kind of scenery was exotic, interesting, beautiful, genuine, and natural. At the very top of this ranking list one could often find the sunset, viewed from a mountaintop or a seaside cliff. Observing this view alone or with silent companions was a form of asethetic worship, an experience of senenity, sanctity, and wholeness.
} 
La concepción que de la naturaleza se tiene en España a finales del siglo xviII difiere mucho de la del norte de Europa. Aunque el texto Frykman y Löfgre hace referencia a una etapa más cercana a nuestros días, el siglo $\mathrm{xx}$, y el estudio español se refiere al siglo XvIII, resulta extremadamente interesante contrastar las diferentes concepciones que se tienen de las zonas verdes en uno y otro lugar.

\section{LAS IDEAS SOBRE LA NATURALEZA EN ESPAÑa A FINALES DEL SIGLO XVIII}

Escogí los tres ejemplos que más adelante voy a estudiar en detalle, para analizar a través de un lugar concreto, en esta ocasión la Casa de Campo de Madrid, lo que podría haber sido la percepción de la naturaleza en torno al siglo XviII. Como se ha dicho más arriba, en este planteamiento hay que ver la concepción de la naturaleza en el Mediterráneo, de forma diferente a la visión del disfrute al aire libre en los países nórdicos. En su obra La tierra esquilmada (1987), Luis Urteaga hace un análisis de las ideas sobre la conservación y la percepción en la cultura española en este marco histórico a través del análisis de los textos de los naturalistas más llamativos de la época, sobre todo, las obras de G. Bowles (1789), A. Cavanilles (1797) y de A. Ponz (1772-1794). Según Urteaga, la vieja concepción mecanicista y estática de ver la naturaleza cambia a finales del siglo xviI y se convierte en una visión dinámica. Si hasta ese momento, la valoración de la naturaleza se debía a la utilidad de sus recursos, ahora se introduce como elemento nuevo en ciertas obras, la idea del goce del paisaje. Cuando Frykman y Löfgren hablan de lo que produce entre los suecos la atracción por la naturaleza, se refieren tanto a la sensación de los inviernos nórdicos con sus noches de frío glacial, como a las vacaciones del verano en la costa. Por el contrario en el Mediterráneo, las circunstancias climatológicas parecen haber tenido mayor influencia en relación con el entorno natural. Entre los textos en que se basa Urteaga, es interesante resaltar el trato que se hace del tema climatológico, sobre todo del calor, que parece ser uno de los aspectos primordiales en la creación de una determinada percepción de la naturaleza más propia los países del sur.

Al recorrer Bowles Castilla nos deja ver su impresión ante un paisaje desolado por falta de árboles. En la tierra de Campos todo está pelado y consumido por el calor (Urteaga 1987: 185).

El autor apunta anotaciones semejantes en la obra de Ponz, quien dice en su descripción del camino entre Madrid y Toledo, que la escasez de 
árboles es lo que hace especialmente desagradable el viaje a los forasteros, acostumbrados a ver países llenos de frondosidad y hermosura. Estrechamente relacionado con el calor está el aspecto de la sombra, a la cual se hace también referencia:

La condición de viajero que durante años disfrutó Ponz le hace valorar, con especial insistencia, los "beneficios" de la sombra. Tanto es así, que en el décimo volumen de su Viaje inventa la historia de un individuo que después de transitar muchas horas bajo el sol abrasador cae en un estado febril. En su delirio, el viajero infortunado tiene visiones futuristas de caminos subterráneos, o protegidos por "toldos" para guarecerse del calor (Ibid.: 186).

\section{REAL CASA DE CAMPO}

Centrándonos ya en el tema de nuestro trabajo, la mayoría de los textos sobre la Casa de Campo, se limitan a la descripción de los jardines, sus trazados y a la estética del lugar. Creo, que aparte de las excelentes aportaciones ya existentes, será también interesante enfocar este espacio verde, creado al fin y a cabo para el recreo y la diversión de un grupo social muy reducido, desde el punto de vista de su rendimiento. Así el objetivo de mi estudio será el uso espacial del terreno durante el marco histórico de la segunda mitad del siglo xvIII hasta principios del $\mathrm{xx}, \mathrm{a}$ través de fuentes de la biblioteca del Palacio Real.

La historia de la Casa de Campo o Real Casa de Campo de Madrid va unida a la de la capitalidad, dado que fue a mediados del siglo XvI; en 1561, cuando Felipe II adquirió esta posesión, entonces conocida como la Casa de Campo de los Vargas (Navascués, Ariza y Tejero Villarreal 1998). Sobre la fecha de la venta varían las informaciones: A. Fernández de los Ríos (1876) y P. Madoz (1847) sitúan la adquisición del terreno en 1559, mientras que autores más modernos como A. Gimeno Pascual (1981), mencionan el año 1560 y otros suelen referirse "a mediados del siglo XVI" para la venta de las tierras. A lo largo de los años siguientes, se añadieron una serie de compras de terrenos a distintos propietarios. La última adquisición para la formación del Real Bosque de la Casa de Campo la efectuó Felipe II en 1583, resultando una demarcación semejante a la que se refleja en el plano de Texeira de 1656. Las construcciones de la posesión eran entonces el edificio principal, la casa-palacio, situada junto a la puerta del río, que Madoz describe como una modesta edificación con dos cuerpos que estaba muy lujosamente adornada en su interior. El parque tuvo su época de mayor esplendor alrededor de la mitad del siglo XvII cuando se celebraron allí algunas fiestas, entre ellas la representación de 
la obra Los tres mayores prodigios, comedia de Calderón de la Barca (1701) que presenciaron sus Majestades en el Real Sitio. Con la pasión por la caza de Carlos III y Carlos IV, el sitio pierde la imagen de esplendor y, mientras la vida social se pasa al Retiro, la Casa de Campo adquiere un nuevo uso exclusivo: la caza. La reina regente María Cristina, ya en el siglo XIX, intenta sacar provecho de la posesión, bien utilizándola en gran parte para la agricultura o en diversos proyectos que pudieran ayudar a compensar los costes de mantenimiento del Real Sitio.

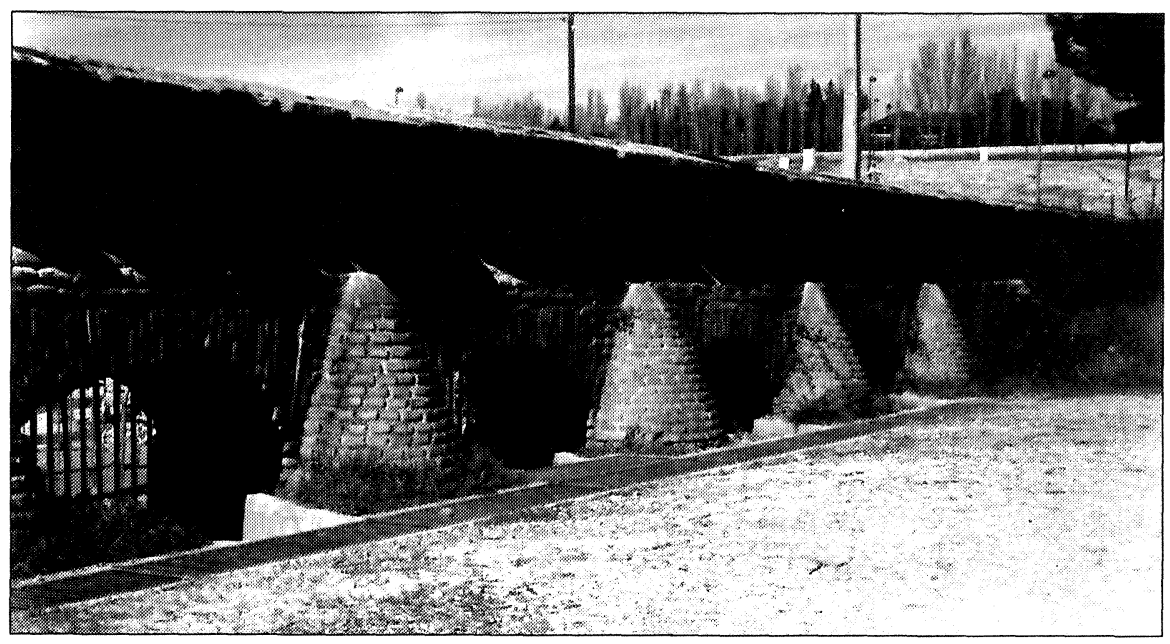

Figura 2.-Las rejas de Sabatini: Arroyo del Prado del Rey.

Foto: Traude Müllauer-Seichter, 2001

\section{LA VIDA DENTRO DE LA CERCA}

Los Sitios Reales, a parte de su núcleo palaciego que se utilizó para el disfrute de la Familia Real y los miembros de la Corte, tenía a la vez un claro destino económico con su arquitectura apropiada y ajustada a los fines específicos de las diversas formas de producción. Relata Virginia Tovar Martín (1990: 259):

Los Sitios Reales [...] evolucionan hacia una serie de ensanches y extensiones, sobre todo en el siglo xviII, constituyéndose el territorio en general, en asiento de importantes poblamientos, algunos al servicio del palacio directamente, y otros con mayor o menor relación con éste, convertidos en auténticos enclaves rurales con sus propias peculiaridades y complejidad, para cuya ordenación en todos los casos fue necesaria la presencia planificadora de los más destacados arquitectos de la Corte. 
Como es comprensible, esta estructura arquitectónica propia de los Sitios Reales, debía deslindarse de la configuración de su función primordial.

Por ello habría que configurar unos tipos de uso estrictamente agrícola, a diferencia de otros de función ganadera, de aquellos que pueden tener como destino una industria artesana derivada del cultivo o los frutos de la ganadería y, por último, los tipos que pudieron entenderse como asentamientos poblacionales, domésticos, en los que posiblemente se hayan de desentrañar diversos niveles, atendiendo a las diferentes responsabilidades de los campesinos. (Tovar Martín 1990: 261)

Dentro de esta "arquitectura suburbana de los Sitios Reales", como técnicamente es denominada por Tovar Martín, aparecen elementos como las cercas o cordones que separaron los sectores productivos, del espacio previsto para el disfrute y el placer. Otros factores divisorios como vallas, tapias o pretil son reiteradamente mencionados en la documentación de estos conjuntos verdes. En la Casa de Campo como en El Pardo o Aranjuez, contamos además con caballerizas, debido a las instalaciones de cuarteles en el terreno. Su tipología, de edificaciones simples y funcionales, solía ser muy parecida en todos los Sitios mencionados.

Volviendo a la Casa de Campo, hay que decir que relativamente pronto ${ }^{4}$ tuvo su propia administración y gobierno, independiente de los demás Sitios Reales. Para el cuidado y mantenimiento de la posesión se contrató una serie de empleados, según precisa Busto y de Jado Cajigal (1876: 49):

Un administrador, un guarda mayor, un jardinero mayor, un hortelano mayor, un interventor, un escribiente, 2 jardineros, 30 guardas y 50 obreros diarios.

Éstos tenían la obligación de vivir junto a sus familias dentro de la cerca del Real Sitio. Es bastante difícil saber cómo transcurriría la vida allí, pero al menos los informes rutinarios, donde figuraban los costes detallados de los Sitios Reales, dejan entender, que se trata de un número notable de personas el que "disfrutaba" aunque de forma diferente, de estos espacios verdes. De estas mismas fuentes se puede obtener la conclusión de que los sueldos en general eran mínimos y en muchas ocasiones los hijos trabajaban sin remuneración. Carmen Simón Palmer escribe sobre la situación en el Retiro a mediados del siglo xvIII:

\footnotetext{
${ }^{i}$ Dice Ana María Gimeno Pascual (1981: 76): «[...] en los primeros años de existencia, como Sitio Real, dependía de la Alcaldía del Pardo. Su separación debió realizarse en los últimos años del siglo xvI, ya que en el año 1597 existen instrucciones particulares para el gobierno de la Casa de Campon.
} 
Sabemos que los sueldos de los jardineros eran muy modestos pero las denuncias continuas evidencian que los complementaron con los beneficios que los mismos jardines producían: aves, peces, frutas o leña. [...] se contrata a muchachos de $16 \mathrm{y}$ 17 años, hijos de viudas de empleados, que se ofrecen voluntarios y sin sueldo con la esperanza de entrar algún día en nómina (Simón Palmer 1991: 37).

En cuanto al alojamiento del personal permanente había varios edificios dentro de la posesión. Acerca de la estructura de las viviendas de obreros podemos observar en el texto de Tovar Martín las siguientes características que se repiten con frecuencia en los diversos Sitios Reales:

Destaca en estos conjuntos la vivienda en la que residen los trabajadores de manera estable o esporádica. Por las descripciones documentales se advierte la presencia permanente de un patio que regula la distribución interior; sin embargo, queremos resaltar el valor superior que se concede a dos piezas que parecen categóricas en la vivienda: el zaguán (lugar de tertulia) y la cocina con sus anejos. Estas casas de labor están, por lo general, inscritas en una trama arquitectónica muy cuidada, desde cuyo centro parten, en ocasiones los caminos de árboles que conducen a los sectores vecinos, al exterior de la posesión real o al propio corazón del Sitio Real (1990: 267).

Cerca del llamado palacio había cuatro casas para los dependientes y otra dentro del jardín donde vivía el capataz. El resto, salvo los guardias, que tenían sus casitas distribuidas por toda la Casa de Campo, los dependientes del Real Sitio habitaban en casas bajas, situadas junto a su unidad laboral, como la Faisanera Vieja, la Casa del Labor, en la Torrecilla o la Casa de Vacas. Aparte de estos núcleos residenciales que servían para el mantenimiento de la parte estética y agrícola del lugar, no hay que olvidar que la posesión estaba dividida en cinco cuarteles: el de Torrecilla, el de Corbatillas, el de Portillo o de Casa-Quemada de los Pino y el de Rodajos, de lo que se puede deducir que habitaban dentro de la cerca de la Casa de Campo, una cantidad considerable de personas. La estructura en el interior del Sitio cubría necesidades parecidas a las de un pueblo, así que contaba con dos iglesias, una en Rodajos y otra en la Torrecilla donde se situó también un cementerio con lo que se cubrieron todas las secuencias del ciclo vital:

A la derecha de la iglesia de la Torrecilla está la casa de labor, con caballeriza, granero, corral con cobertizo y cocina para los mozos; en el cerrillo inmediato, el Campo Santo para los dependientes de la posesión (Fernández de los Ríos 1876: 386).

Acerca del contacto con la vida fuera de la cerca no se puede obtener mucha información de las fuentes. Sobre la arquitectura de tales en- 
tidades destinadas a la producción, podemos recurrir a las aclaraciones que hace Virginia Tovar Martín (1990: 266) respecto a este asunto:

La casa de labor engloba, por lo general, dos partes diferenciadas. En sus límites se integran una serie de estancias que se destinan a útiles y áreas en general de cultivo y guarda. Establos, graneros, dependencias para almacenamiento, lagares, bodegas, molinos, anejos de valor arquitectónico muy parecido, que facilitan las tareas o el propio autoconsumo. El gallinero, la perrera, etc., son muy frecuentes en los límites cercanos a la vivienda. Son construcciones de un solo piso, organizaciones primarias que, a veces, se suceden en cadena o se articulan en escuadra. El conjunto llega a formular en algunos casos el cortijo o la granja con una perfecta integración o reparto racional de todos los instrumentos funcionales.

Una de las escasas noticias sobre la convivencia humana dentro de estas unidades económicas que representaban los Sitios Reales se encuentra en la obra de Liger de Oxerre sobre la Economía de la Casa de Campo (1720), donde el autor dedica todo el capítulo IV a las normas de comportamiento de los empleados que residían en este terreno. Aquí se refiere a las obligaciones del Padre y la Madre de las Familias que en general suelen coincidir con las de la Iglesia católica, como es normal dentro de su contexto histórico. Más adelante se refiere más concretamente a las obligaciones del Padre de Familias en relación con la economía de las haciendas de la Casa de Campo:

Ha de tener un libro, en que diariamente se anote, y escriba con gran puntualidad, y cuidado del día, en que entra a servirle cada uno de los Criados en su Casa, y el salario, que ha de ganar; procurando notar asimismo en dicho libro el dinero, que les fuere dando a cuenta; porque esta regla será el mejor medio de no hazerse agravio a sí mismo, ni a los Criados, que le sirven. Ha de ser muy exacto, y cuidadoso en cobrar con puntualidad, lo que se le estuviere debiendo legítimamente (Liger de Oxerre 1720: 60).

Los consejos en cuanto al pago de sueldos parecían no coincidir con lo que era la realidad en aquellos días o al menos con el caso de otro Sitio Real, el Retiro, donde se produjeron incluso huelgas de los empleados por no haber sido pagados durante meses.

Si deseare estar bien servido, lo logrará pagando puntualmente sus salarios a los Criados y Jornaleros que se emplean en el cultivo de sus Tierras; cuidando también de que se les asista con el sustento, que les pertenece (Ibid.: 61).

Oxerre apuesta por la sabiduría en lo que se refiere a la conveniencia de los que tenían que mandar a los criados cuando escribe: 
La vigilancia de un Padre de Familia se conocerá también en el cuidado, que ha de poner en la manutención de todo, lo que está debaxo de su dominio, previniendo algunos accidentes perjudiciales, que pudieran suceder; y nunca lucirá más su inteligencia en el exercicio de su empleo, que quando se viere que sabe distinguir unas labores de otras, haziendo que se executen cada una según su orden, prefiriendo siempre lo que produce utilidad, a lo que sólo sirve para el gusto (Ibid.: 62).

En consecuencia, se refiere también a las obligaciones de la mujer en el mantenimiento de las unidades económicas, aunque estas reglas son muy generales y de ellas no se obtiene más información sobre las peculiaridades del lugar.

La mujer del Padre de Familias tomando para sí, lo que la podrá convenir de las reglas, y obligaciones, que se han señalado a su Marido, debe también estar advertida, de no perder de vista a sus Criadas y cuidar que lo interior de la Casa (que está ordinariamente fiado a su vigilancia) esté siempre governado con muy buen orden: que nada se vea arrastrar por los suelos: que cada cosa esté en su lugar sin confusión, y que la limpieza, y asseo, que es verdaderamente la señal y nota de una persona bien nacida, resplandezca en todo (Ibid.: 64).

En el fondo, es poco lo que se puede saber sobre el trato de los empleados de las posesiones, aunque se puede sacar alguna conclusión del arreglo en cuanto a los alimentos:

Hay diversos modos de hazer Pan. Uno es Pan Casero, que es el que cada Ciudadano hace cocer en su Casa de Campo, o de la Ciudad; y este Pan se haze ordinariamente de harina de trigo, y come de ordinario. Otro Pan, que se haze para la Familia y Criados del Campo, que amassa de harina de trigo, y centeno; y de este género de Pan usan comunmente para su sustento las personas que viven con pocas conveniencias en los Lugares cortos (Ibid.: 65).

Sobre la movilidad del personal hacia la villa y el reglamento de visitas por sus familiares o amigos dentro de la cerca no se aporta información. Sí hay conocimiento sobre la restricción de salir de la posesión evitándose así que se realizara algún otro trabajo aparte. Práctica entonces común para aumentar los ingresos de la familia, como ocurría en el caso de los jardineros en situaciones comparables en otros Sitios Reales, como el del Retiro:

Además de los beneficios que obtenían de su trabajo redondeaban su sueldo con otros extraordinarios en casas de particulares. Aunque les estaba prohibido, era difícil para el Jardinero mayor negarse a las peticiones, que aún hoy se conservan, para que les concediera permiso para plantar los jardincitos de las familias Medinaceli, Floridablanca, Alcañices, etc. (Simón Palmer 1991: 40) 


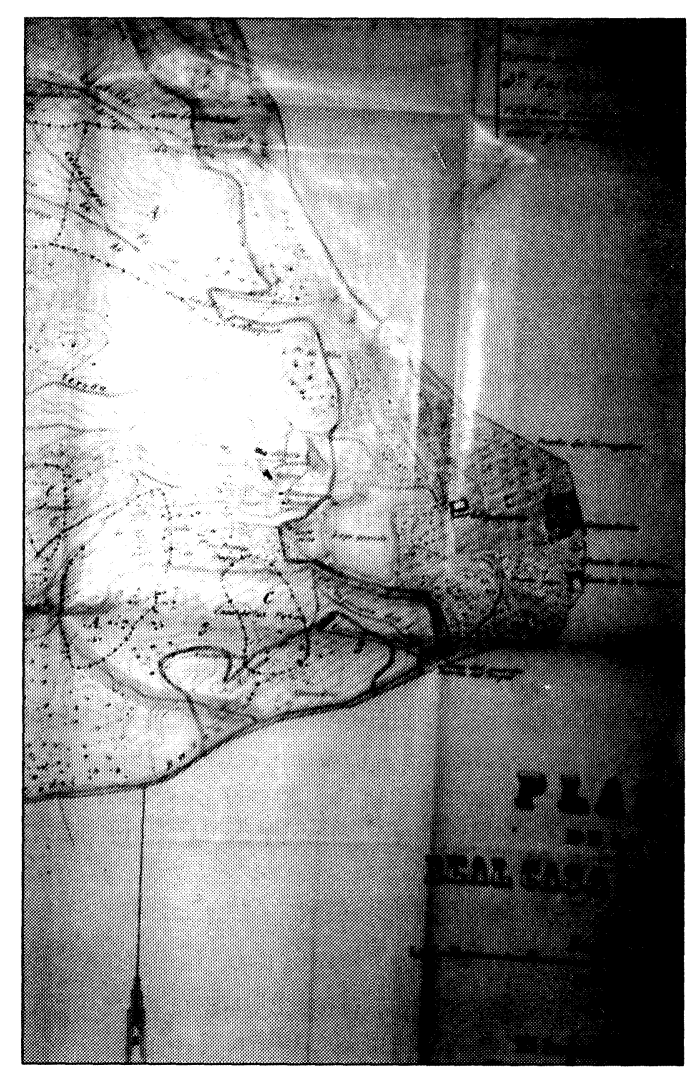

Figura 3.-La Casa de Campo en 1910: Biblioteca del Palacio Real, Signatura Arch. 1/Cart/10/2; Foto: Margarita del Olmo.

\section{ENTRE LO PRIVADO Y LO PÚBLICO}

En relación con el Retiro, accesible para los madrileños desde los años sesenta del siglo XviII, la Casa de Campo abrió relativamente tarde sus puertas al público. Habrá que esperar hasta el año 1931 cuando, el Ministro de Hacienda, Indalecio Prieto, firma el acto de entrega de la Casa de Campo al Ayuntamiento de Madrid. Aunque el pueblo llano tuvo poco tiempo para el disfrute de este espacio verde tan propio de la capital, ya que cinco años después el lugar se convierte en uno de los campos de batalla durante la Guerra Civil. Si la fecha del 5 de mayo de 1931 supuso la apertura como espacio público, los años de la guerra borraron las huellas históricas.

El parque urbano que se sitúa con el crecimiento de la urbe cada vez más en el corazón de la capital, es aún posesión privada, pero se 
abre bajo ciertas condiciones más y más a un público que ansiosamente desea invadir el espacio verde. Una de las primeras guías sobre la Casa de Campo, publicada en 1901, muestra el sitio en una situación transitoria:

Permiso: Los poseedores de esta GUÍA podrán visitar por una vez, con tres personas que les acompañen, la Real Posesión, presentando antes el libro en la Portería mayor de la Intendencia de Palacio, donde se sellará el cuaderno inferior de la derecha de esta página en que se lee Permiso (Jorreto: 1901: 1).

Para comprender el valor que tiene la posesión para la capital, el autor la compara con otras fincas de la misma índole que poseen otras monarquías, añadiendo su fin primordial de recreo sin lucro; aunque esta afirmación no es exacta, como se refleja en las fuentes de las que se va a hablar más adelante.

Sin perdonar gasto ni sacrificio alguno, se fomenta constantemente el trabajo de embellecimiento, que produce la subsistencia de centenares de obreros, hasta el punto de invertirse en jornales más de 20.000 pesetas cada año, y, a la manera que el Buen Retiro es un higiénico pulmón de la Corte por O., lo es por el S. la Casa de Campo (Ibid.: 1).

En esta guía se confunden la orientación, tanto del Retiro como de la Casa de Campo. A lo largo del texto el autor incluye varias referencias un tanto confusas sobre la situación dentro del terreno de la Casa de Campo.

El acceso entonces era bastante difícil y más si se utilizaban los medios públicos. Jorreto aconseja a los visitantes coger el tranvía en la Puerta del Sol, que llega hasta la cuesta de San Vicente para entrar al Sitio por la puerta del Rey, cruzando en este lugar el río Manzanares:

Pero, antes de llegar ustedes a la Real Casa de Campo, tienen que pasar por una decepción, por un río avergonzado de llamarse así, porque, en vez de cristalinas y abundantes aguas, acopia sobre sus cauce cenagoso fango, cuyos pútridos miasmas inficionan el ambiente, diezmando todos los años la población de los contornos (Ibid.: 6).

Para ahorrarse estas impresiones, el autor describe un recorrido alternativo para los que acuden en carruajes propios:

Si ustedes desean conocer todo lo mejor posible la Real Casa de Campo, visitándola en carruaje propio, les aconsejamos que no abandonen los nuevos caminos: pueden dar la vuelta completa al gran estanque, comenzando a la izquierda del mismo y siguiendo por la calle de Alfonso XII, plaza de Siete Hermanas, calle de 
los Plátanos y de María Teresa, hasta salir a la de María Cristina, carretera de Castilla, deteniéndose en la Casa de Vacas y camino de la Granjilla, que termina en la Puerta del Medianil, subiendo después por el camino de este nombre hasta encontrar nuevamente la calle de María Cristina (Ibid.: 28).

Este recorrido contiene en grandes líneas, todas las atracciones a las que se invita en la guía de visita. Sigue una serie de cortas explicaciones de los lugares mencionados en el circuito. Más interesantes resultan las informaciones sobre los curiosos y exactísimos estudios de tipos y costumbres madrileñas en el momento de la entrada:

Esperando que el portero abra la cancela de hierro, á un lado los vagos dispuestos con su caña de pescar a que, sentados a la orilla del estanque, inmóviles e impasibles, [...] y al otro lado los infelices trabajadores que desde los barrios más extremos de la capital vienen a ganarse su sustento (Ibid.: 28).

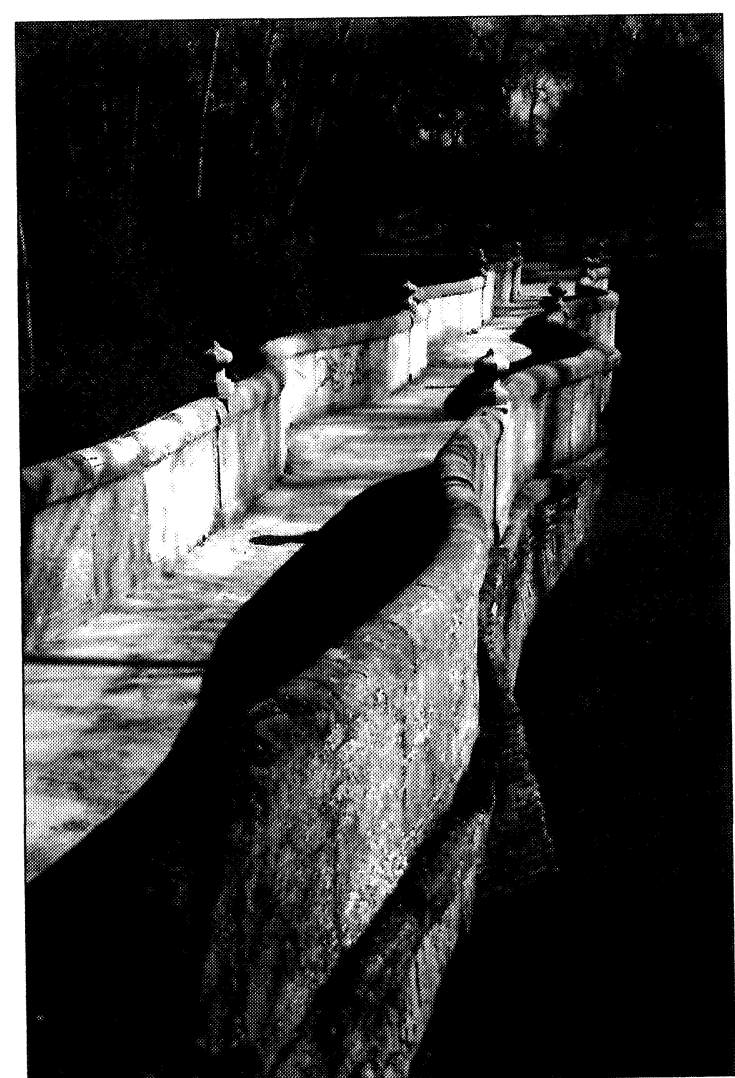

Figura 4.-Los Puentes de Sabatini: Puente de la Culebra. Foto: Traude Müllauer-Seichter, 2001-03-12.
Aunque no hay más información sobre este punto, el Sitio ya seguramente era accesible también para otras clases de la sociedad, las cuales, al parecer, no tenían que pagar para entrar en la posesión. Para alimentar la curiosidad, el autor dibuja los diferentes tipos: paisajistas, que toman apuntes artísticos, estudiantes, cuyo libro no se les ha ocurrido abrir, la joven pálida, que bebe del manantial para recobrar el apetito, etc. Estas descripciones demuestran que el lugar ya había adquirido las características de espacio público, aunque figuraba todavía como posesión privada. Por lo que se refiere a la guía, queda por mencionar que su precio 
era de dos pesetas y con otras dos, se entregaba en la librería de Fernando Fé un retrato de la reina con el autógrafo de la soberana en oro. Hasta aquí el interesante intento de comercializar el lado estético del espacio verde urbano.

\section{El LADO OPUESTO DE LA ESTÉTICA — USO ECONÓMICO DEL ESPACIO VERDE}

Aunque la obtención de grandes beneficios no podía ser el fin primordial de los Reales Sitios, había que calcular cómo mantener unas posesiones de tal tamaño, sobre todo, cuando se reducían las dotaciones para los Sitios Reales ${ }^{5}$. A continuación voy a exponer dos ejemplos, fruto de los intentos de buscar nuevas alternativas económicas para este espacio en concreto. En el primer caso, se trata de la propuesta de Manuel del Busto y de Jado Cajigal en el año 1876, de instalar una fábrica de gusanos de seda. El segundo la creación del Colegio Real de Don Alfonso en 1858 sobre el arroyo de Meaquez (Ramírez Arcas 1858). Ninguno de estos proyectos tan ambiciosos llegó a realizarse.

\section{Manuel del Busto y de Jado Cajigal: La Fábrica de Seda}

En su proyecto de aprovechamiento de los terrenos de la Real Casa de Campo, llevado a cabo con autorización de S.M. Alfonso XII, Manuel del Busto y de Jado Cajigal, ingeniero agrónomo, propone instalar una fábrica de seda como incentivo, que colaboraría de forma positiva al provecho sacado hasta el momento de la producción agraria de la posesión. Defiende la implantación de esta rama industrial como la forma que menos restaría al sitio su destino primordial de recreo:

El carácter que debe afectar el cultivo de la Casa de Campo no es el mismo que podría aconsejarse para una finca particular en donde se tratase sacar el mayor producto posible; es preciso por el contrario que la de que se trata conserve el carácter de posesión de recreo que la es propio y que no debemos ni podemos quitarle, dejándola en su mayor extensión para las Augustas Personas que han de descansar en aquel sitio de los cuidados que les ocasiona su elevada misión; no es posible por lo tanto aprovechar más terreno que aquel cuyo cultivo no se oponga a la referida aplicación y aún esto dentro de ciertos límites (Busto y de Jado Cajigal 1876: 4).

\footnotetext{
5 Como era el caso del Retiro en 1743 , cuando se redujo por Real Orden de Felipe V la donación del sitio de 30.000 a 20.000 pesos.
} 
Así, no se puede aconsejar emprender la industria de la cría de cerdo o del cultivo de la vid, indudablemente de más rendimiento, pero requieren, en cambio, el uso de más terreno. Por el contrario aduce en favor de su propuesta:

La circunstancia de existir en la posesión un número considerable de moreras indica que debe emprenderse la cría del gusano de seda, para el aprovechamiento de sus hojas. Esta industria [...] pudiéndose además prestarse un inmenso servicio a la industria española en otros tiempos tan floreciente y hoy tan decaída por desgracia (Ibid.: 4).

En un examen sobre la producción de seda en España, comparada con la de Italia, Francia, Turquía, Grecia, Austria, Portugal y Alemania, Busto y de Jado (1876) intenta demostrar la riqueza que supone para un país el desarrollo de esta industria que equipara a la de la plata. Compara la situación climatológica de Zaragoza, Murcia, Cartagena y otros puntos de España para llegar a la conclusión de que estas ciudades tienen climas más desfavorables para la cría del gusano de seda que Madrid.

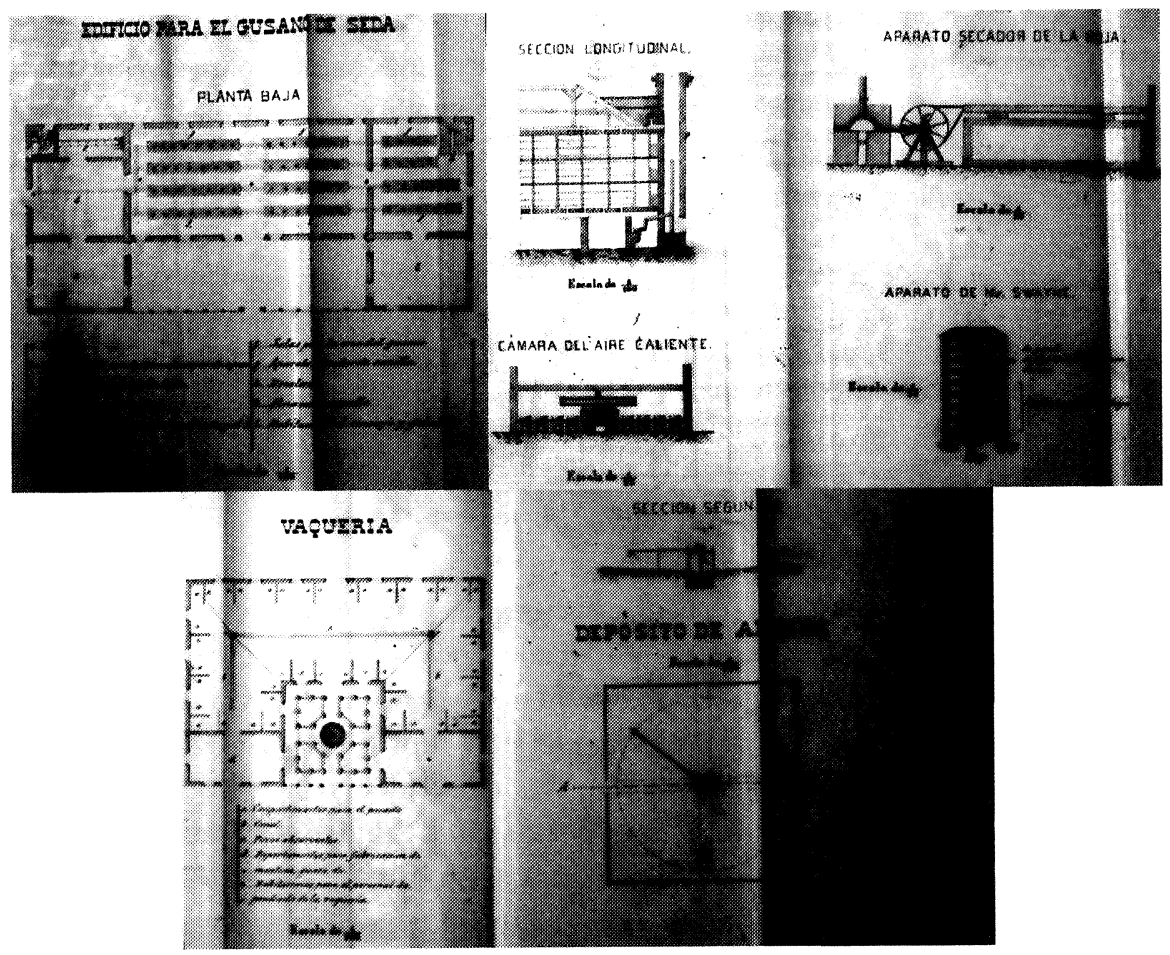

Figura 5.-Edificio para el gusano de seda: Biblioteca del Palacio Real, Signatura II/3536; Foto: Margarita del Olmo. 
Aunque no llegara a realizarse el proyecto, la situación que se mostraba en el marco histórico alimentaba las esperanzas de esta rama industrial. En Madrid, se trabajaban entonces varias especies de manufacturas de seda y su fabricación se diversificó en diferentes ramos de producción. En el año 1757 existían sólo en la ciudad 41 talleres que se dedicaban a la seda, alcanzando en el año 1777 la cantidad de 100 (Larruga 1787: 96). La historia de la seda en la capital la describe Larruga en sus Memorias:

La [historia de la] seda es muy corta, porque excepto las moreras del canal, son raras las que se encuentran en tierra de Madrid. Uno de los primeros que se dedicaron en la corte a criar gusanos y secar seda, fue Don Pedro de Sobrevilla, vecino y del comercio de ella: para esto procuró fomentar esta cosecha en los lugares de Navalagamella, Colmenar del Arroyo, Valdemorillo y otros de la Serranía inmediata al Real Sitio del Escorial. A los principios hizo los hilados en Navalagamella y en la villa de Estevan-Ambrán: posteriormente y desde el año de 1771, la hiló dentro de Madrid en una casa fábrica que para este fin tuvo en la calle de Segovia, en el sitio que llaman los corralillos, a donde hacía conducir de los referidos lugares, la seda en capullo por los mismos cosecheros. En el de 1779, estableció esta cría en el canal de Manzanares, con acuerdo del Intendente de él, baxo de cierta contrata (Larruga 1787: 65).

Es probable que Busto y de Jado viera una salida para la Casa de Campo por su intrínseca riqueza que se presentaba en forma de moreras, de las cuales dependía la cría y en la cual Larruga no ponía la misma fe cuando se refiere al tema:

La cosecha de seda en esta provincia, según el número de moreras que ya están criadas, podría rendir al año ocho mil libras de seda; pero según noticias que se han tomado no les sale muy bien la cuenta a los que se dedican á criarla, y éste será sin duda el motivo de ser muy poca la cantidad de seda que se coge (Ibid.: 67).

\section{El proyecto del Colegio Real de Don Alfonso}

Este proyecto consistía en la creación de una institución de enseñanza preparatoria para las carreras especiales por cuenta exclusiva del Estado y se presentó en el año 1858, debiendo el nombre propuesto al Príncipe de Asturias. Bajo su protección, debería reunir una escogida juventud con el título de Colegiales Alfonsinos. La experiencia ha mostrado que ni el Estado ni tampoco las empresas particulares podían realizar ese objetivo por carencia de medios. De esta forma, se justifica la inversión diciendo que casi en todos los países de "la Europa moderna" ha sido adoptado ya un sistema mixto, es decir, una unión de fondos con el fin de una formación sólida y eficaz. Dice Ramírez Arcas en la presentación: 
La carencia de esta clase de establecimientos que desgraciadamente se lamenta en España, afecta a los intereses morales del país, que tan ligados deben estar con su política. Por no haber siquiera un colegio donde no sólo adquiera la juventud la ciencia que necesita para ingresar con el debido desarrollo intelectual, en las escuelas especiales, sino también el perfeccionamiento moral que una dirección continua y eficaz debe procurarle, muchos padres de familia se ven en la precisión de hacer durante algunos años, grandes dispendios que generalmente son infructuosos tanto porque de ordinario es insuficiente en sus medios y en sus resultados la enseñanza de asignaturas libres, que ofrecen los establecimientos creados por el interés particular, cuanto porque los alumnos no se hallan bajo la influencia del régimen y disciplina convenientes (Ramírez Arcas 1858:1).

La realización del proyecto del colegio solventaría una necesidad del país incluyendo una amplia formación, no sólo en las profesiones particularmente consagradas a la agricultura, la industria o al comercio, sino también en la carrera de armas. Los cargos previstos con los cuales contaba el colegio eran los siguientes. Aparte del subdirector encargado de la administración, economía y disciplina, la plantilla habría contado con un regente de estudios, un capellán, los profesores de las diversas asignaturas, un médico, un dentista, inspectores de noche y los dependientes y domésticos. En cuanto al edificio que se pensaba construir, existían los siguientes planes:

El edificio tendrá dos departamentos; el uno, en el ala derecha donde habitarán los colegiales hasta cumplir doce años, a fin de que los cuidados especiales que necesitan los niños hasta esta edad, estén completamente atendidos. Una dama de S.M. será nombrada por la Reina para que inspeccione el régimen higiénico y la asistencia de los colegiales de esta edad. En el ala izquierda del edificio habitarán los alumnos mayores. Todo colegial que deba parar en enfermería será cuidado en ella con esmero por el número de hermanas de la Congregación de San Vicente de Paul que se señale por el médico del establecimiento; a no ser que el padre o encargado estimare conveniente designar otro facultativo, y personalmente o por medio de su familia prestarle asistencia en local especial que se tendrá destinado al efecto (Ibid.: 1).

La admisión de los colegiales requería que previamente, el aspirante fuera presentado por su padre en el establecimiento, que hubiera recibido una primera enseñanza elemental y adjuntase un certificado de bautismo. Estaba previsto escoger alumnos de entre 9 y 14 años, siendo obligatorio que el colegial estuviera vacunado y no padeciera ninguna enfermedad contagiosa. La presentación del proyecto sigue con un detallado listado del uniforme de los colegiales que incluye hasta los precios en tres diferentes tallas.

A continuación se propuso el plan de enseñanza que abarca en su total seis años: en los dos primeros se proyectaba dar instrucción moral y religiosa, gramática castellana, francés, inglés, geografía, historia, dibujo 


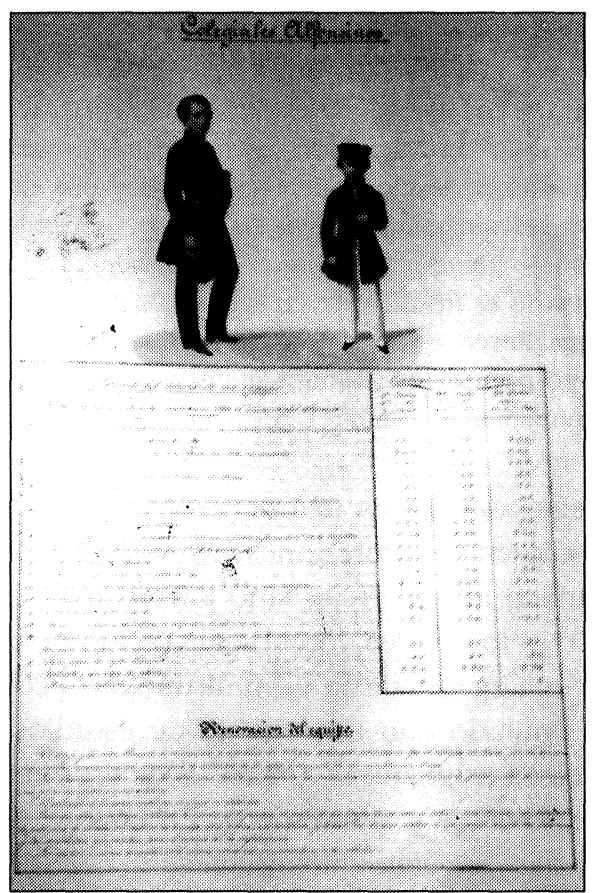

Figura 6.-Proyecto del Colegio Real de don Alfonso sobre el arroyo de Meaquez en la Real Casa de Campo: Biblioteca del Palacio Real, Signatura 1-V-1858; Foto: Traude Müllauer-Seichter. geométrico y canto. En los siguientes se añaden contabilidad, elementos físicos, tecnología mineral, aritmética y matemáticas. Se pensaba impartir clase de zoología e higiene, cultivo y botánica, mecánica, pintura de enseñanza superior y complementar el campo de idiomas con latín, alemán e italiano. Los gastos de estudios eran de 1500 reales por cada trimestre a lo que se sumaban 200 reales por el uso de la cama y otros 20 para las reparaciones de los objetos que normalmente se estropearían durante el curso.

Las últimas dos páginas del proyecto presentado se ocupan con los planos de los edificios y jardines del Colegio que habían sido construidos sobre el arroyo de Meaquez y tenía que limitar en su entrada con el camino del Batán por un lado y, por el otro, con el de la puerta de Rodajos. Igual que en el caso del proyecto de la fábrica de gusanos de seda, no se encuentran más referencias sobre el porvenir del Colegio. Como otras ideas en cuanto al uso del terreno de la Casa de Campo, fuera del ámbito estético, estos dos proyectos se quedaron en intento.

Con estos breves apuntes, resultado de un trabajo recién iniciado sobre espacios verdes públicos, al que seguramente se pueden sumar muchos ejemplos más, he pretendido añadir al enfoque estético, con que se suele abordar el tema, otro punto de vista de estudio: el lado económico de los aespacios de placern.

\section{BIBLIOGRAFÍA CITADA}

BOWLES, G. 1789. Introducción a la historia natural y a la geografía fisica de España. Madrid.

Busto y DE JADO CAJIGAL, M. 1876. Proyecto de Aprovechamiento de los terrenos de la Real Casa de Campo. Madrid. 
BUXÓ I REY, M. J. 1999. "El aire libre: los jardines en la construcción de la identidad” en J.A. González Alcantud y C. Lisón (eds.): El aire: mitos y ritos y realidades. Barcelona.

CALDERÓN DE LA BARCA, P. 1701. Loa para la comedia los tres prestigios. Biblioteca de Palacio Real: VIII/17147, Teatro Español Vol. XIX.

CAVANILlES, A. J. 1797. Observaciones sobre la bistoria natural, geografia, agricultura, población y frutos del reyno de Valencia. Madrid.

FERNÁNDEZ DE LOS Ríos, A. 1876. Guía de Madrid. Manual del Madrileño y del forastero. Madrid (Edición Facsimilar, 1982).

FrYKMAN, J. y O. LÖFGREN. 1987. Culture Builders: A Historical Anthropology of Middle Class Life. London.

Gimeno Pascual, A. M. 1981. "La Casa de Campo" en Jardines Clásicos Madrileños: 67-76. Museo Municipal: Ayuntamiento de Madrid.

JORRETO, M. 1901. Monografias Artisticas: Real Casa de Campo. Madrid.

LARRUGA, E. 1787. Memorias políticas y económicas sobre los frutos, comercio, fábricas $y$ minas de España. Tomo II. Madrid.

LIGER DE OXERRE, L. 1720. Economía de la Casa de Campo, Tomo I, Madrid

MADOZ, P. 1847. Diccionario geográfico-estadístico-histórico de España y sus Posesiones de Ultramar. Madrid, Tomo X. Madrid.

Navascués, P., C. Ariza, y B. Tejero Villareal. 1998. “La Casa de Campo” en Carmen Añón y José Luis Sancho (eds.), Jardin y Naturaleza en el reinado de Felipe II: 420-439. Madrid.

PONZ, A. 1772-1794. Viaje de España o cartas en que se da noticia de las cosas más apreciables o dignas de saberse que bay en ella. 18 Tomos. Madrid. (Edición facsímil, Madrid 1947).

Ramírez ARCAS, A. 1858. Proyecto del Colegio Real de Don Alfonso fundado por SS. MM. sobre el arroyo de los Meaquez en la Real Casa de Campo. Madrid.

RuBio DíAZ, A. 1993. "La ciudad como sistema útil: para una genealogía de las relaciones modernas entre ciudad, naturaleza y planificación", en Naturaleza urbanizada. Estudios sobre el verde en la ciudad. Málaga.

Simón PAlmer, M. C. 1991. El Retiro. Parque de Madrid. Madrid.

TOVAR MARTín, V. 1990. "Arquitectura suburbana en los Sitios Reales (siglo XVIII)", en A. Cea, M. Fernández Montes y A. Sánchez Gómez (coords.), Arquitectura Popular en España. Madrid.

URTEAGA, L. 1987. La tierra esquilmada. Las ideas sobre la conservación de la naturaleza en la cultura española del siglo XVII. Barcelona. 